IRA-International Journal of Education \& Multidisciplinary Studies

ISSN 2455-2526; Vol.07, Issue 02 (2017)

Pg. no. $130-137$

Institute of Research Advances

http://research-advances.org/index.php/IJEMS

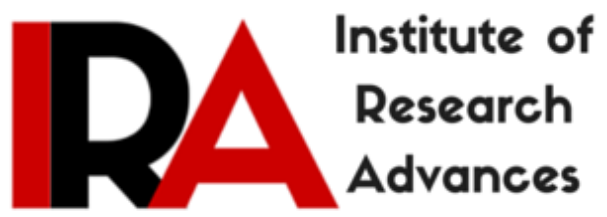

\title{
Verifiability and Falsifiability as Parameters for Scientific Methodology
}

\section{Sandhya Shankar}

PhD Research Scholar, Jawaharlal Nehru University, India.

Type of Review: Peer Reviewed.

DOI: http://dx.doi.org/10.21013/jems.v7.n2.p10

\section{How to cite this paper:}

Shankar, S. (2017). Verifiability and Falsifiability as Parameters for Scientific Methodology. IRA International Journal of Education and Multidisciplinary Studies (ISSN 2455-2526), 7(2), 130137. doi:http://dx.doi.org/10.21013/jems.v7.n2.p10

(C) Author.

\section{(cc) BY-NC}

This work is licensed under a Creative Commons Attribution-Non Commercial 4.0 International License subject to proper citation to the publication source of the work.

Disclaimer: The scholarly papers as reviewed and published by the Institute of Research Advances (IRA) are the views and opinions of their respective authors and are not the views or opinions of the IRA. The IRA disclaims of any harm or loss caused due to the published content to any party. 


\section{INTRODUCTION}

The question of 'how do we come to know' has been the search of mankind since time immemorial. Neither has there been a consensus for that question nor there will be. Many a great minds have looked into this, coming up with various perspectives.

Two such varying perspectives in this field are empiricism and rationalism. While the former emphasizes that experience (through senses) is the only source of knowledge the latter upholds that there is something beyond the sense experience, the mind that is the source of knowledge.

The shift towards a scientific phase from that of the earlier theological and metaphysical phase gained popularity with positivism, where progress of human knowledge was considered in identifying truths through scientific methods. In this scientific journey towards knowing the world emphasis was on empirically observable things. It was believed that there are no ideas which come into our head without being dependent on our perceptions, thereby on our experience.

The basis of classical science was considered getting empirical observations. It had to be a systematic way of studying what is out there. Purpose of science was considered to be limited to things which can be observed, thus being connected to a means of being verified.

This paper thus looks into the notion of verifiability as an important parameter of scientific methodology and its importance as asserted by logical positivists.

But this criteria of scientific method was challenged by another criteria, that of falsifiability. The next section will look into falsifiability as another parameter of scientific methodology.

Since these parameters have been discussed widely among philosophers, this paper shall be focusing on the views of A. J. Ayer and Sir Karl Popper regarding the same.

Furthermore, its application and relevance to the field of linguistics will also be discussed.

\section{VERIFIABILITY AS A CRITERION FOR SCIENCE}

Logical positivist relied on the observations based on experience as being scientific ${ }^{1}$. They saw science as a way to reach the truth. It was the way to understand the world and thus be able to predict and control it. The key approach to this was through experimentation. Explanation of natural laws was attained through manipulation and observation.

Just knowing was not enough. That which was claimed had to be proved through observable means in order to be accepted by others. In around 1920, many philosophers, mathematicians and scientists came together in Vienna (their group known as the Vienna circle) under the leadership of Moritz Schlick to reconcile philosophy with the new sciences and to evaluate truth with respect to empirical verifiability, thus emerged the logical positivists ${ }^{2}$. Their goal was to uncover the truth.

A $\mathrm{J}$ Ayer who was one of the followers of this school. He made logical positivism well $\mathrm{known}^{3}$ in England, especially through his book titled 'Language, Truth and Logic' in 1936. This book contained many of the central doctrines of logical positivist school of thought.

\footnotetext{
${ }^{1}$ Logical positivism. Philosophy pages. 2011

${ }^{2}$ Ibid.

${ }^{3}$ Stanford Encyclopedia of Philosophy. A J Ayer.
} 
He presents his views on verifiability as occupying an essential role in determining the sensible from the nonsensical theories of philosophy. As per him, the verification principle is a tool in revealing the useful questions of philosophical inquiry.

Philosophy for him is wholly critical. It is an activity of linguistic analysis. For him "A sentence is factually significant if, and only if, we know how to verify the proposition it purports to express" (Ayer, 1936). He states the example of a sentence like "there are mountains on the other side of moon". Now such a statement even though not immediately verifiable (especially at that point of time when space explorations were not as developed) could be verified if there are appropriate technology for it, and therefore significant. He thus distinguished between verification by practice and verification by principle. The above example is a case of verification by principle while an example of the former would be something like, 'there is a dog on couch'. There are, but, certain sentences which cannot be verified either in practice or in principle, for example sentences like 'the absolute is heavy'. Now such a sentence cannot be verified at all, and thus as per him it is of no significance and to be discarded.

To quote Ayer " the issue may be defined as the problem of finding a criterion by which we can distinguish between assertions (statements, systems of statements) which belong to the empirical sciences, and assertions which may be described as 'metaphysical'. According to a solution proposed by Wittgenstein, this demarcation is to be achieved with the help of the idea of 'meaning' or 'sense': every meaningful or sensible proposition must be a truth function of 'atomic' propositions, i.e., it must be logically completely reducible to (or deducible from) singular observation statements. If some alleged statement turns out not to be so reducible, then it is 'meaningless' or 'nonsensical' or 'metaphysical' or a 'pseudo-proposition'. Thus metaphysics is meaningless nonsense.” (Ayer, 1936)

He further distinguishes between strong and weak verification principles. A proposition has strong verification principle if its truth could be confirmed through experience while it has weak verification principle if it is possible for experience to make it probable.

He says that depending on strong verification criteria cannot always be feasible, say in a situation where the proposition is something like 'arsenic is poisonous', because it cannot be 'verified' with certainty finite number of times. Thus for him, a liberal criterion would then be, not whether the proposition can be verified with certainty but instead is there an observation which would be relevant for verifying.

Verifiability takes such an important position for him that he rejects metaphysics on the basis that it cannot be verified either in principle or in practice and thereby terms it nonsensical and not to be included within philosophy. Only tautologies and empirical hypotheses are significant propositions. Tautologies are true because as per him we never let anything else be true.

\section{TRUTH OF FORMAL LOGIC AND MATHEMATICS}

"Where the empiricist encounters difficulty is with the truths of formal logic and mathematics, for they appear to everyone to be necessary and certain." (Ayer, 1936: 88). To solve such a problem, Ayer himself explained that in case of a mathematical expression such as ' $2+12=14$ ' if we get a count of say 10 , then surely we do not refute that the truth of $2+12$ is not 14, instead we say that we calculated wrongly.

In such cases of formal logic we take the case of excluded middle, which states that the proposition must either be true or false. When we are negating a sentence then we are not always contradicting the original proposition. 


\section{ANALYTIC PROPOSITIONS AND LINGUISTICS}

The term 'linguistics' is not used here in terms of its phonological and syntactic structures but instead in the philosophical sense of its meaning making, i.e. how is a sentence considered meaningful, their truth values etc.

Ayer considers propositions of philosophy not to be factual but instead linguistic. He further says that philosophy is a branch of logic which is concerned with consequences of our definitions and not with questions of empirical facts.

For him there were two kinds of meaningful sentences, those which could be verified by observation and those which were true by themselves. The latter kinds of sentences were known as analytic sentences.

Kant introduces these terms analytic and synthetic in his book Critique of Pure Reason to differentiate between two kinds of propositions. According to him

Analytic propositions are true by the virtue of their meaning.

Synthetic propositions are true by how their meaning relates to the world.

An example of analytic proposition would be a sentence such as 'all bachelors are unmarried' its meaning can be understood by the understanding the terms in use. While a synthetic proposition would be something like 'all bachelors are unhappy". In such a case it is dependent on the context, on the possible worlds were this proposition is being uttered to be true or not.

He further proposes a distinction among propositions as in being 'a priori' or 'a posteriori'.

A priori propositions are those whose justification does not depend upon experience. The proposition can be validated by experience, but need not be grounded in it.

A posteriori propositions are those whose justification does not rely upon experience. Their validation is grounded in experience.

Together they make four types of possible propositions:

1) Analytic a priori proposition

2) Synthetic a priori proposition

3) Analytic a posteriori proposition

4) Synthetic a posteriori proposition

Ayer's metaphysical knowledge would come under the second category, which is synthetic a priori, that is its meaning is relates to the outside world but it cannot be validated by experience and thus as per verification principle such propositions are ruled out as nonsensical.

Mathematical truths which are based on their own axiomatic statements which are true by itself fall under the first category of analytic a priori propositions.

Kant had claimed that the third category as self contradictory, something which is true by itself will then not be dependent upon experience for its justification.

\section{CRITICISM OF AYER'S VERIFICATIONISM}

For Ayer statements were meaningful if the propositions were either tautologies or else verifiable by means of observation. Take a sentence for example as: 'there is a book kept on the table'. This proposition is not a tautology. If it has to be verified by means of observation, then the suitable thing would be to go and see whether the book is there on the table or not. But is this enough? Suppose I go till there and 
suddenly the book disappears or else it transforms into something else and then again back to the same book. So will it be right to say that the proposition I stated earlier is true by verification? There will always be some room for mistake. As per Ayer if a proposition cannot be verified, as in the above case, either directly or even in a weak sense then is it termed as meaningless?

Thus as Freidrich Waismann ${ }^{4}$ points out in his paper, 'Verifiability', that it is not possible to conclusively verify even a proposition that looks like a case of simple verification. He says there are always possibilities that something might turn up to alter the truth value of that proposition however rare this chance might be. He calls this the case of 'Open texture', i.e. a term used to suggest the possibility of vagueness in empirical statements. According to Waismann, there cannot be a statement which can be verified with finality because no word has the meaning which covers all possible gaps. For example, take the word 'book' now there might be an object lying on the table which I state as 'this is a book', but when I examine it, it seems that there is just one page in there or else the front cover is missing. That is to say that, one can never exhaustively cover all the possibilities in determining the meaning of the term and thus it is not always possible to verify a statement empirically.

Waismann raises another point regarding whether verification just provides the meaning of the proposition or something more? According to him, through verification we are not just getting the meaning of the proposition, but also that it tells us about its use, that is the use in grammar, in language.

He further states that "The question of the verification arises only when we come across a new sort of combination of words". For example when we hear a sentence such as 'the dog barks' we do not bother to verify, for the meaning is understood by the words used. But in case of a statement like 'the dog thinks' one inquires further into what it means.

Ayer's another criticism was for rejecting metaphysics, issues of ethics and aesthetics as nonsensical, only because it did not fall into a certain criteria of verifiability by observation.

The statements that we utter are not necessarily always verifiable as said above. Statements that are about our emotions or else state of mind are not empirically verifiable. For example statements like 'I am hungry', or else 'I saw a dream about unicorns' are not verifiable, in fact 'unicorns' are mythical creatures, but when someone utters these statements they make perfect sense. Thus verifiability as a criterion does not apply to all linguistics statements.

One of the theories of semantics that stands in conflict with verifiability is Putnam's Twin Earth experiment. It considers the truth condition of a statement to be dependent on truth of that proposition in the possible worlds. It assumes that there are multiple possible worlds and that the proposition needs to be true in any one of them. It was developed by Hilary Putnam in his 1973 paper Meaning and Reference ${ }^{5}$. A drawback that empirical verifiability poses in linguistics can be seen by taking this theory as the background. If we take the theory of possible worlds then the truth condition of a statement depends on the truth of that proposition in the possible worlds, an example often given is that of 'this is water'. Suppose I say a statement in a world, were water means $\mathrm{H}_{2} 0$, its chemical formula. Now in say another world I might see a liquid which is just like water in its characteristics but say instead of the chemical composition of $\mathrm{H}_{2} \mathrm{O}$ it has say a chemical formula $\mathrm{XYZ}$, then the reference differs and thus affecting its truth conditions. This just cannot be validated by verification.

\footnotetext{
${ }^{4}$ Waissman (1945)

5 “Twin Earth thought experiment" Accessed online on $1^{\text {st }}$ November, 2016, URL : https://en.wikipedia.org/wiki/Twin_Earth_thought_experiment)
} 


\section{POST POSITIVIST THEORIES}

Positivist theories on distinguishing the meaningful from the non meaningful and its way to establish the truth was realized not to apply in all cases, thus emerged the post positivist theories, as a criticism of logical positivists. The Most common feature of post positivism is critical realism. There is a reality independent of our thinking that science can study and not just the empirically observable ones. Unlike positivist theirs is not a search to uncover the truth. In fact they believe that what is required is to strive for getting it right about reality even though one might never be able to reach that goal of reality.

Karl Popper criticized logical positivist views of verifiability with introducing the concept of falsifiability instead as a criterion of demarcation.

In linguistics on the other hand, there are various theories for identifying the meaning of propositions, truth conditions of possible worlds being one of them. It was started by Gottfried Leibniz and later more elaborated by Kripke. Verifiability does not seem to work in this respect but 'corroboration' as Popper calls it is a reasonable way. He says that "empirical content of a statement increases with its degree of falsifiability: the more a statement forbids, the more it says about the world of experience". (Popper, 1970)

This works on the process of elimination, if there are many contenders then instead of choosing a particular one to be true, start eliminating the ones which are false, so that you narrow down on the ones which can be corroborated.

\section{KARL POPPER AND FALSIFIABILITY}

As against Ayers verifiability, Sir Karl Popper proposes the notion of falsifiability as a criterion of distinguishing a scientific statement from a non scientific one. His main reason for proposing the notion of falsifiability was the problem of induction. He explained that it is not possible to universalize a particular hypothesis just on the basis of observable verification. One of his famous examples in this regard is that of the white swans. Suppose I have a hypothesis that 'all swans are white'. Now I set to prove this by observing many white swans but then I come across a black swan. In such a case the hypothesis stands incorrect no matter how many white swans have I seen.

He called this falsification as the 'criteria of demarcation'. It separated the scientific theories from the non scientific ones. That is the theories which could be falsified were considered to be scientific while others were not.

To explain the difference between the two, Popper assumes a scientific theory ' $T$ ' which predicts an observation 'O', i.e. If $\mathrm{T}$ then $\mathrm{O}$. suppose we get an $\mathrm{O}$, but this will does not necessarily mean $\mathrm{T}$. But in case of not $\mathrm{O}$, then we can surely say that it will be not $\mathrm{T}$. This was the deduction approach.

Popper provides distinction between the psychology of knowledge which he says deals with empirical facts, and the logic of knowledge which is concerned only with logical relations. He also says that conceiving an idea need not be based on logical analysis. It could be something like a creative intuition or "an irrational element". From this new idea hypothesis could then be drawn in a logical deductive manner. He offers a step by step procedure for this:

The proposed or theory's hypothesis is logically compared within that system. Next it is checked to see whether it is an empirical or scientific character or whether it is a tautology. Then it is compared with other theories to see whether it will be a scientific advancement as compared to the other theories. Finally the theory is tested using empirical applications. 
Thus for Popper science is a 'revolution in permanence' and criticism is important for science. But he gets an opposing view in Kuhn who says that revolution is exceptional and indeed extra scientific. For Popper scientific change is rational 'logic of discovery' while Kuhn terms it as 'psychology of discovery'. Kuhn emphasis that it's the social collection which helps in a paradigm shift while for Popper it depends on the individual's reasons.

A criticism often heard of Popper's falsifiability is that just outrightly falsifying thereby refuting a theory does not mean progress in science. But the falsification that Popper proposes is not just about the refuting a particular theory but in a different sense too, which Imre Lakatos explains in his paper 'Falsification and the Methodology of Scientific Research Program'. He argues that as per Popper a theory is theoretically progressive if a new theory, say $\mathrm{T}^{\prime}$, is proposed in place of the old theory $\mathrm{T}$, with more novel facts which also explain the propositions made in the old theory, then the new theory $\mathrm{T}^{\prime}$ falsifies $\mathrm{T}$ but it provides progress as it provides new information also. In fact the more novel facts a theory proposes the more progressive it is.

As per Popper it is not possible to ascertain real truth, it is just that we move from one circle to another. Theories are a continuation to this, a constant attempt to reach that goal.

\section{CONCLUSION}

This paper discussed the notion of verifiability as considered by A J Ayer. For him and other logical positivists verification was the way science was to get its truth. They believed in empiricism, key approach to anything scientific was through empirical experiments. There was an attempt to discern natural laws through direct manipulation and observation. They received many criticisms mainly because of their statement that anything that cannot be verified or was a tautology was nonsense, thereby rejecting metaphysics from philosophy. Popper was not a logical positivist, he rejected the idea of problem of induction in verification and proposed a more suitable notion of falsifiability. His notion was not that everything in science should be falsifiable, but instead it should be capable of being falsified. Focus should be on theories to be corroborated instead of just being verified. For Popper, falsifiability did not mean an outright denial or refusal of the theory that was proposed but instead it also meant that the proposed theory is not able to answer all the questions and the new theory proposed is capable of corroborating the earlier theories as well as the new problems posed.

Mathematical logic is based on a set of axioms which are true in themselves. If we get some data which does not match the proposed one then it does not immediately falsify the theory but instead the procedure is checked once again because formal logic is based on tautologies.

\section{REFERENCES}

- $\quad$ Ayer A. J. (1936), Language Truth and Logic, London: Penguin Books ( $2^{\text {nd }}$ Edition).

- Kemerling, Garth. (2011), "Logical Positivism", [Online: Web] Accessed 30 Oct. 2016 URL: http://www.philosophypages.com/hy/6q.htm

- Lakatos, Imre. (1970), "Falsification and the methodology of Scientific Research Programs", in Imre Lakatos (1970) Criticism and the Growth of Knowledge, Cambridge: Cambridge university Press

- Popper, Karl. (1935), The Logic of Scientific Discovery. E library: Taylor and Francis. (2002)

- Popper, Karl. (1970), "Normal Science and its Dangers", in Imre Lakatos (1970) Criticism and the Growth of Knowledge, Cambridge: Cambridge University Press 
- Shuttleworth, Martyn. (2009), "History of the Scientific Method", [Online: Web] Accessed 30 Oct. 2016 URL: http://explorable.com/history-of-the-scientific-method.html

- Stanford Encyclopedia of Philosophy, "Philosophy of Linguistics", [Online: Web] Accessed 30 Oct. 2016 URL: http://plato.stanford.edu/entries/linguistics/.

- "Twin Earth thought experiment" Accessed online on $1^{\text {st }}$ November, 2016, URL : https://en.wikipedia.org/wiki/Twin_Earth_thought_experiment

- Waismann, Friedrich. (1945), "Verifiability", [Online: Web] Accessed 30 Oct. 2016 URL: www.ditext.com/waismann/verifiability.html.

- Wikipedia, "Analytic-Synthetic Distinction", [Online: Web] Accessed 30 Oct. 2016 URL: http://en.wikipedia.org/wiki/Analytic\%E2\%80\%93synthetic_distinction. 